\title{
EFEITO RESIDUAL DA FERTIRRIGAÇÃO COM ÁGUA RESIDUÁRIA DE BOVINOCULTURA NA QUALIDADE DE UM SOLO ARGILO-ARENOSO
}

\author{
Samanta Ferreira Bortoni ${ }^{1}$, Jonathas Batista Gonçalves Silva ${ }^{2} \&$ Camila Pinho de Sousa $^{3}$ \\ 1 - Engenheira Ambiental e Sanitarista, Doutoranda em Engenharia Civil na COPPE/UFRJ - RJ, samanta.bortoni@engenharia.ufjf.br \\ 2 - Engenheiro Agrícola e Ambiental, Professor na UFJF/Campos Juiz de Fora - MG, jonathas.silva.ufjf@gmail.com \\ 3 - Engenheira Agrônoma, Professora na UFRRJ/Campos Seropédica - RJ, camilafepi@hotmail.com
}

\author{
Palavras-chave: \\ Bioindicadores \\ Fertirrigação \\ Água residual \\ Qualidade do solo
}

\begin{abstract}
RESUMO
Nos últimos anos, a crescente geração de resíduos e sua destinação inadequada têm gerado relevantes impactos ambientais. A fertirrigação é uma das técnicas de reaproveitamento e destinação dos resíduos, com benefícios para a cultura e solo, porém, pouco se sabe sobre o efeito residual da fertirrigação no solo. Diante disso, o presente trabalho teve como objetivo a análise de um solo argilo-arenoso previamente fertirrigado com água residuária de bovinocultura (ARB), utilizando o rabanete (Raphanussativus) como bioindicador. Foram utilizados cinco tratamentos com diferentes porcentagens de água residuária: T1 ( $0 \%$ ARB); T2 (50\% ARB); T3 (100\% ARB); T4 (200\% ARB) e T5 (300\% ARB). Avaliou-se o comprimento da parte aérea, diâmetro do bulbo, massa seca da parte aérea e raiz, desempenho fotossintético e fitotoxicidade da cultura em estudo para os diferentes tratamentos. A água residuária de bovinocultura elevou a fertilidade do solo, o que resultou no aumento do desenvolvimento do rabanete, no que diz respeito ao comprimento da parte aérea, diâmetro do bulbo, massa seca da parte aérea e raiz e desempenho fotossintético. Entretanto, para o tratamento com 300\% de água residuária (T5), foi observado um decréscimo no comprimento da parte aérea, no diâmetro do bulbo e na massa seca da parte aérea e raiz, possivelmente, devido ao aumento das concentrações de sódio no solo. De modo geral, a aplicação de doses de ARB que suplanta expressivamente a demanda nutricional das culturas pode acarretar o aumento expressivo dos níveis de sódio no solo e, com isso, a diminuição do desempenho das culturas.
\end{abstract}

\section{Keywords:}

Bio-indicators

Fertigation

Soil Quality

Wastewater

\section{RESIDUAL EFFECT OF FERTIGATION WITH WASTEWATER FROM CATTLE FARMS (ARB) ON A CLAY-SANDY SOIL QUALITY}

\section{ABSTRACT}

Nowadays, the increase in waste generation as well as its inappropriate disposal has significantly affected the environment. Fertigation is one of the techniques for waste recycling and/or safely disposing with benefits to crop and soil. However, the residual effects of soil fertigation still require further studies. The aim of this study was to analyze clay-sandy soil previously fertigated with wastewater from cattle farms (ARB) using radishes (Raphanussativus) as bio-indicators. It was used five treatments with different percentages of wastewater: T1 (0\% ARB); T2 (50\% ARB); T3 (100\% ARB); T4 $(200 \%$ ARB); e T5 (300\% ARB). The characteristics of the evaluated radishes were the leaves' length, bulbs' diameter, leaves and roots' dry mass, photosynthetic performance, as well as the radishes' phytotoxicity for all the different treatments. The wastewater from the cattle farms increased the soil fertility, which resulted in an increase in radish growth regarding the leaves' length, bulbs' diameter and the leaves and roots' dry mass. However, for the treatment with $300 \%$ of residual ARB (T5), the development of the leaves' length, bulbs' diameter and the leaves and roots' dry mass decreased, possibly, due to the increase in soil sodium levels. Overall, the application of excessive doses of ARB much larger than the crops' nutritional demand can increase substantially the levels of sodium in the soil, decreasing the crops' development. 


\section{INTRODUÇÃO}

Nas últimas décadas, a população vem aumentando exponencialmente, motivando uma demanda crescente por alimentos. Segundo o relatório publicado pela Organização das Nações Unidas, a população mundial em julho de 2015 atingiu 7,3 bilhões e a expectativa para 2016 é de um acréscimo de 83 milhões de pessoas. O crescimento populacional até 2050 é considerado inevitável, sendo a probabilidade de $80 \%$ da população atingir valores entre 9,4 e 10 bilhões (UNITED NATIONS, 2015). Para responder a essa demanda, a produção mundial de alimentos deve crescer cerca de $70 \%$ até 2050 (FAO, 2009).

$\mathrm{O}$ aumento da produção de leite, segundo estimativa da Organização das Nações Unidas para Agricultura e Alimentação (FAO) para o ano de 2015 , foi de $2 \%$, totalizando uma produção de 805 milhões de toneladas (FAO, 2015). No ano de 2011, o Brasil ocupou o quinto lugar no ranking mundial de produção leiteira (IFNC, 2012), contabilizando 32,091 bilhões de litros de leite produzidos e arrecadando um valor aproximado de 24 bilhões de reais (IBGE, 2011).

Durante o processo produtivo do leite, são geradas águas residuárias, uma vez que para atender as condições sanitárias, os galões, ordenhadoras e linhas de condução do leite devem ser limpos a cada sessão de ordenha. A quantidade de água residuária (AR) gerada nesses criatórios de animais dependerá da quantidade de água usada na limpeza, desperdiçada pelos animais nos bebedouros, excretadas, além das águas pluviais que podem se juntar aos dejetos dos animais (MATOS, 2010).

Para Campos et al. (2002) apud Silva (2012), a quantidade total de efluente gerada diariamente no confinamento de vacas leiteiras varia de 9 a $12 \%$ do peso vivo do animal, sendo função também do modo de limpeza e desinfecção da unidade de produção. A disposição adequada das águas residuárias de bovinocultura $(\mathrm{ARB})$ apresenta-se como um desafio para produtores e especialistas, uma vez que compreende aspectos econômicos, sanitários e técnicos (SILVA, 2012). A situação agrava-se, visto que a ARB é rica em material orgânico, sólidos totais e nutrientes, tais como o nitrogênio e o potássio, representando um potencial poluidor do meio ambiente, caso sejam destinados de maneira incorreta.

A fertirrigação tem se mostrado uma maneira efetiva de disposição e reaproveitamento de águas residuárias advindas de processos agroindustriais, possibilitando o aumento da produtividade, qualidade dos produtos colhidos, redução de custos de produção e da poluição ambiental, além de promover melhoria nas características químicas, físicas e biológicas do solo (SILVA, 2012).

Diversos estudos analisaram as consequências da disposição das águas residuárias no solo, constatando um melhor desempenho das culturas e aumento da qualidade do solo. Erthal et al. (2010) relataram um ligeiro aumento no $\mathrm{pH}$, capacidade de troca catiônica, índice de saturação por bases, aumento das concentrações de cálcio, magnésio e potássio trocáveis nas camadas mais superficiais do solo. Do mesmo modo, Sousa et al. (2013) constataram uma maior produtividade das culturas fertirrigadas, se comparadas às provenientes de adubação convencional.

Entretanto, pouco se sabe sobre o efeito residual da fertirrigação no solo. Diante disso, o presente trabalho teve como objetivo a análise de um solo previamente fertirrigado com água residuária de bovinocultura, utilizando o rabanete Crimson Gigante como bioindicador.

\section{MATERIAIS E MÉTODOS}

$\mathrm{O}$ ensaio ocorreu na área experimental da Universidade Federal de Juiz de Fora, no município de Juiz de Fora - Minas Gerais, na Zona da Mata mineira. Segundo a classificação climatológica de W. Köppen, a cidade possui um clima tropical de altitude, caracterizado por verões quentes e chuvosos e invernos com baixas temperaturas e relativamente secos (CESAMA, 2010). O plantio e desenvolvimento das sementes ocorreram nos meses de março a maio ( $1^{\circ}$ ciclo $)$ e de maio a julho ( $2^{\circ}$ ciclo) de 2014.

O solo utilizado no experimento foi concedido pela Universidade Federal Rural do Rio de Janeiro (UFRRJ) após ter sido fertirrigado, visando a produção de pepinos nos meses de junho a setembro de 2013. Este recebeu diferentes doses 
de água residuária de bovinocultura (ARB), considerando a demanda nutricional necessária para o bom desenvolvimento da cultura do pepino. Assim, o solo foi dividido em cinco tratamentos: T1 (0\% ARB); T2 (50\% ARB); T3 (100\% ARB); T4 (200\% ARB) e T5 (300\% ARB).
Amostras de cada tipo de solo passaram por análises físico-químicas no Laboratório de Rotina e de Física do Solo da Universidade Federal de Viçosa, realizadas segundo Embrapa (2011). Na tabela 1 e 2, está representada a caracterização química e física do solo, respectivamente.

Tabela 1. Caracterização química dos solos fertirrigados com diferentes doses de ARB: T1 ( $0 \%$ ARB); T2 (50\% ARB); T3 (100\% ARB); T4 (200\% ARB) e T5 (300\% ARB).

\begin{tabular}{|c|c|c|c|c|c|}
\hline \multirow[b]{2}{*}{ Parâmetro* } & \multicolumn{5}{|c|}{ Solos } \\
\hline & T1 & $\mathrm{T} 2$ & T3 & T4 & T5 \\
\hline pH $\mathrm{H}_{2} \mathrm{O}$ & 5,30 & 5,29 & 5,33 & 5,65 & 5,78 \\
\hline $\mathrm{P}\left(\mathrm{mg} . \mathrm{dm}^{-3}\right)$ & 4,3 & 11,2 & 7,7 & 11,5 & 13,1 \\
\hline $\mathrm{K}\left(\mathrm{mg} \mathrm{dm}^{-3}\right)$ & 10 & 55 & 56 & 77 & 128 \\
\hline $\mathrm{Na}\left(\mathrm{mg} \mathrm{dm}^{-3}\right)$ & 10,0 & 27,0 & 26,0 & 44,0 & 48,1 \\
\hline $\mathrm{Ca}^{2+}\left(\mathrm{cmol}_{\mathrm{c}} \cdot \mathrm{dm}^{-3}\right)$ & 1,42 & 1,73 & 1,67 & 1,84 & 1,89 \\
\hline $\mathrm{Mg}^{2+}\left(\mathrm{cmol}_{\mathrm{c}} \cdot \mathrm{dm}^{-3}\right)$ & 0,94 & 1,30 & 1,28 & 1,78 & 1,83 \\
\hline $\mathrm{Al}^{3+}\left(\mathrm{cmol}_{\mathrm{c}} \cdot \mathrm{dm}^{-3}\right)$ & 0,20 & 0,10 & 0,10 & 0,00 & 0,00 \\
\hline $\mathrm{H}+\mathrm{Al}\left(\mathrm{cmol}_{\mathrm{c}} \mathrm{dm}^{-3}\right)$ & 2,3 & 2,3 & 1,8 & 1,8 & 1,4 \\
\hline $\mathrm{SB}\left(\mathrm{cmol}_{\mathrm{c}} \mathrm{dm}^{-3}\right)$ & 2,43 & 3,29 & 3,21 & 4,01 & 4,26 \\
\hline CTC $\left(\mathrm{cmol}_{\mathrm{c}} \cdot \mathrm{dm}^{-3}\right)$ & 2,63 & 3,39 & 3,31 & 4,01 & 4,26 \\
\hline$T\left(\mathrm{cmol}_{\mathrm{c}} \cdot \mathrm{dm}^{-3}\right)$ & 4,73 & 5,59 & 5,01 & 5,81 & 5,66 \\
\hline V (\%) & 51,4 & 58,9 & 64,1 & 69,0 & 75,3 \\
\hline m (\%) & 7,6 & 2,9 & 3,0 & 0,0 & 0,0 \\
\hline ISNa (\%) & 0,92 & 2,10 & 2,26 & 3,29 & 3,69 \\
\hline MO (dag.Kg ${ }^{-1}$ ) & 0,26 & 0,90 & 0,64 & 0,77 & 0,77 \\
\hline P- Rem (mg.L $\left.{ }^{-1}\right)$ & 27,3 & 25,6 & 26,1 & 27,9 & 31,3 \\
\hline $\mathrm{Cu}\left(\mathrm{mg.dm}^{-3}\right)$ & 0,38 & 0,40 & 0,31 & 0,32 & 0,26 \\
\hline Mn (mg.dm m $\left.{ }^{-3}\right)$ & 25,9 & 35,7 & 32,1 & 32,3 & 24,4 \\
\hline $\mathrm{Fe}\left(\mathrm{mg} \cdot \mathrm{dm}^{-3}\right)$ & 61,7 & 73,4 & 65,2 & 53,9 & 29,4 \\
\hline Zn $\left(\right.$ mg.dm $\left.^{-3}\right)$ & 3,66 & 3,76 & 4,04 & 3,64 & 2,60 \\
\hline PST (\%) & 0,85 & 2,15 & 2,40 & 3,27 & 3,70 \\
\hline
\end{tabular}

* pH $\mathrm{H}_{2} \mathrm{O}$ - pH em água; $\mathrm{P}$ - fósforo; $\mathrm{K}$ - potássio; $\mathrm{Na}$ - sódio; $\mathrm{Ca}^{2+}$ - íon cálcio; $\mathrm{Mg}^{2+}$-magnésio; $\mathrm{Al}^{3+}$ - alumínio; $\mathrm{H}+\mathrm{Al}$ - $\mathrm{Extrator}$ acetato de cálcio; SB - soma de bases trocáveis; CTC - capacidade catiônica efetiva; T - capacidade de troca catiônica a pH 7,0; V - índice de saturação por bases; $\mathrm{m}$ - índice de saturação por alumínio; ISNa - índice de saturação por sódio; MO - matéria orgânica; P- Rem - fósforo remanescente; $\mathrm{Cu}$ - cobre; Mn - Manganês; Fe - ferro; Zn - zinco; PST - porcentagem de sódio trocável.

Tabela 2. Caracterização física e classe textural dos solos fertirrigados com diferentes doses de ARB: T1 (0\% ARB); T2 (50\% ARB); T3 (100\% ARB); T4 (200\% ARB) e T5 (300\% ARB).

\begin{tabular}{ccccc}
\hline & $\begin{array}{c}\text { Densidade da } \\
\text { partícula }\end{array}$ & $\begin{array}{c}\text { Densidade do } \\
\text { solo }\end{array}$ & $\begin{array}{c}\text { Condutividade } \\
\text { elétrica }\end{array}$ & \\
\hline Amostra & $\left(\mathbf{K g . d m}^{-3}\right)$ & & $\left(\mathbf{d S . m}^{-1}\right)$ & Classe Textural \\
\hline T1 & 2,73 & 1,26 & 0,053 & Franco-Argili-Arenosa \\
\hline T2 & 2,80 & 1,20 & 0,112 & Franco-Argili-Arenosa \\
\hline T3 & 2,68 & 1,21 & 0,101 & Argilo-Arenosa \\
\hline T4 & 2,75 & 1,15 & 0,152 & Argilo-Arenosa \\
\hline T5 & 2,70 & 1,19 & 0,197 & Franco-Argili-Arenosa \\
\hline
\end{tabular}


A fertirrigação do solo em estudo foi realizada mediante o uso da água residuária de bovinocultura (ARB), proveniente da limpeza de criadouros de gado confinado. AARB foi analisada no Laboratório de Qualidade de Água, do Departamento de Engenharia da Universidade Federal Rural do Rio de Janeiro e sua caracterização encontra-se descrita na tabela 3 .

Tabela 3. Caracterização da água residuária de bovinocultura proveniente da limpeza de criadouros de gado confinado.

\begin{tabular}{lc}
\hline \multicolumn{2}{c}{ Parâmetros analisados } \\
\hline $\mathrm{pH}$ & 7,4 \\
\hline Condutividade Elétrica & 2,5 \\
\hline Sólidos Totais $(\mathrm{mg} / \mathrm{L})$ & 22100 \\
\hline $\mathrm{DBO}(\mathrm{mg} / \mathrm{L})$ & 4355 \\
\hline $\mathrm{DQO}(\mathrm{mg} / \mathrm{L})$ & 15600 \\
\hline Nitrogênio Total $(\mathrm{mg} / \mathrm{L})$ & 472,3 \\
\hline Nitrito + Nitrato $(\mathrm{mg} / \mathrm{L})$ & 97,1 \\
\hline $\mathrm{NTK}(\mathrm{mg} / \mathrm{L})$ & 366,7 \\
\hline $\mathrm{Na}(\mathrm{mg} / \mathrm{L})$ & 13,0 \\
\hline $\mathrm{Ca}(\mathrm{mg} / \mathrm{L})$ & 42,9 \\
\hline
\end{tabular}

A preparação do experimento iniciou-se no dia 18 de fevereiro de 2014, quando os solos foram destorroados e homogeneizados. No dia 13 de março de 2014, foi realizada a montagem dos vasos para o plantio das sementes de rabanete da cultivar Crimson Gigante. Foram utilizados 15 vasos, sendo 3 réplicas para cada um dos 5 tipos de tratamento. Inicialmente, os vasos receberam uma camada de brita ao fundo e, então, foram preenchidos com solo até distar, aproximadamente, $2 \mathrm{~cm}$ da borda superior do vaso. $\mathrm{O}$ experimento foi realizado segundo um delineamento inteiramente casualizado (DIC).

Em cada vaso, foram plantadas três sementes a cerca de $2 \mathrm{~cm}$ de profundidade, distando aproximadamente $2 \mathrm{~cm}$ umas das outras, formando um triângulo. Duas semanas após o plantio, ocorreu o desbaste das plantas, permanecendo somente a mais desenvolvida de cada vaso.

O manejo da irrigação da cultura em estudo ocorreu segundo turnos de rega diários, com auxílio de uma proveta graduada. A metodologia utilizada na quantificação da lâmina necessária para $o$ atendimento da demanda evapotranspirométrica da cultura foi a de Penman - Monteith, sendo os dados climatológicos necessários obtidos do site do Instituto Nacional de Meteorologia - INMET. Foram utilizados valores para coeficiente de cultura $\left(\mathrm{K}_{\mathrm{c}}\right)$, de acordo com Malavolta (1997). $\mathrm{O}$ valor de $\mathrm{K}_{\mathrm{c}}$ variou de acordo com o estágio de desenvolvimento da cultura: do início do plantio até o décimo dia, o $\mathrm{K}_{\mathrm{c}}$ foi de 0,5 ; do décimo primeiro dia ao vigésimo, $\mathrm{K}_{\mathrm{c}}=0,65$; do vigésimo primeiro dia ao trigésimo dia, $\mathrm{K}_{\mathrm{c}}=0,75$ e no restante dos dias, $\mathrm{K}_{\mathrm{c}}=0,8$.

Após a colheita da cultura, o comprimento da parte aérea da planta (utilizando o comprimento da maior folha), o diâmetro do bulbo e a massa seca foram analisados no Laboratório de Monitoramento Ambiental I - Água e Efluentes da UFRRJ.

A análise estatística do experimento consistiu, inicialmente, no estabelecimento de hipóteses de nulidade $\left(\mathrm{H}_{0}\right)$ e a alternativa $\left(\mathrm{H}_{1}\right)$ para cada um dos quatro parâmetros analisados: comprimento da parte aérea, diâmetro do bulbo, massa seca da raiz e massa seca da parte aérea. Posteriormente, os dados foram submetidos a uma Análise de Variância (ANOVA), considerando um nível de significância de $5 \%$, onde foi utilizado o software SISVAR (FERREIRA, 2014). Após a ANOVA, foi realizado o ajuste de modelo para o caso de aceitação de $\mathrm{H}_{1}$, utilizando o software SigmaPlot Versão 13.0. Também foi realizada a análise do desempenho do aparato fotossintético, utilizando um fluorômetro portátil (HandyPEA, Hansatech, King's Lynn, Norkfolk, UK) e calculando os parâmetros do teste JIP (STRASSER \& STRASSER (1995) apud SOUSA et al. (2012)).

Por fim, a análise visual de fitotoxicidade consistiu na comparação entre os padrões previstos pela literatura para ausência ou excesso de determinado nutriente na cultura e as anomalias observadas nos rabanetes ao longo do $1^{\circ}$ e $2^{\circ}$ ciclo. As análises basearam-se nas fotos obtidas durante o experimento e no livro "Avaliação do Estado Nutricional das Plantas - princípios e aplicações" (MALAVOLTA et. al, 1997).

\section{RESULTADOS E DISCUSSÃO}

Na figura 1, estão representados resultados de crescimento: comprimento da parte aérea, diâmetro 
do bulbo, massa seca da parte aérea e massa seca da raiz, respectivamente, (a), (b), (c) e (d), para o $1^{\circ}$ e $2^{\circ}$ ciclo.

Na figura 1 (a), o desenvolvimento da parte aérea apresenta uma tendência quadrática (até o ponto analisado). No $1^{\circ}$ ciclo, observa-se que para uma dose de $230 \%$ de ARB, o comprimento da parte aérea foi máximo, evidenciando que doses maiores que esta podem causar inibição do crescimento de futuros cultivares. Esta redução do crescimento do rabanete pode estar associada à presença de elementos que inibem o desenvolvimento da planta, tais como o sódio, que é um micronutriente e, consequentemente, elevadas concentrações deste íon no solo podem acarretar estresse hídrico, salino, desequilíbrio nutricional e toxicidade à cultura (FERREIRA, 2007; DUTRA,2008; SCHOSSLER et. al, 2010).

Fonseca et. al (2010) estudaram os efeitos da salinidade na germinação de rabanetes, constatando valores maiores de comprimento da parte aérea e da raiz na ausência de $\mathrm{NaCl}$. Os autores também destacam a queda significativa da germinação das sementes do rabanete com o aumento do $\mathrm{NaCl}$. Entretanto, os efeitos da salinidade não foram observados nesse trabalho, uma vez que o limiar para a cultura do rabanete é de $1,2 \mathrm{dS} \mathrm{m}^{-1}$ e os valores de condutividade elétrica encontrados na análise do solo não ultrapassam $0,2 \mathrm{dS} \mathrm{m}^{-1}$.

O mesmo vale para o $2^{\circ}$ ciclo, porém este apresentou o máximo comprimento a uma dose de $190 \%$ de ARB. Possivelmente, o decréscimo da dose máxima está associado ao fato de que o $1^{\circ}$ ciclo possuía uma maior disponibilidade de

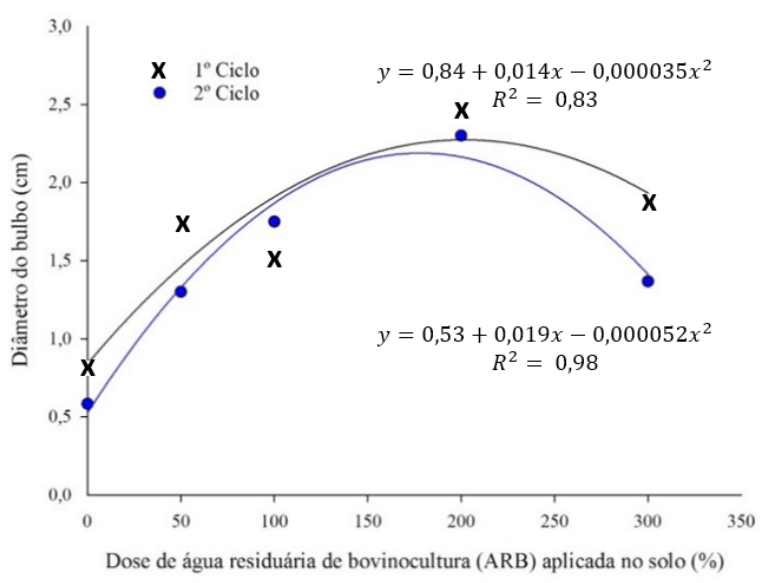

(b)

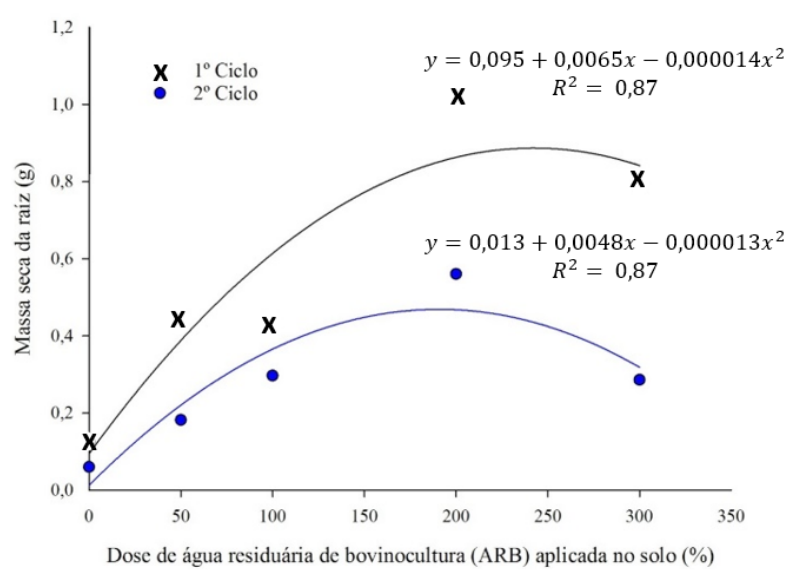

(d)

Figura 1. Resultados de crescimento: comprimento da parte aérea, diâmetro do bulbo, massa seca da parte aérea e massa seca da raiz 
nutrientes essenciais ao seu desenvolvimento se comparado ao $2^{\circ}$ ciclo, uma vez que o mesmo solo foi utilizado.

De maneira geral, o aumento crescente da parte aérea do bioindicador para os tratamentos T2, T3 e T4, em relação ao controle T1, pode ser explicado pelo aumento da fertilidade do solo, visto que o rabanete é uma cultura que exige solo fértil (COSTA et. al, 2006 apud SILVA, 2016). A ARB, uma vez aplicada ao solo, permitiu a mineralização da matéria orgânica, disponibilizando macronutrientes, como nitrogênio, fósforo e potássio, e micronutrientes, como zinco e cobre no solo, mesmo 6 meses depois. Maia et. al (2011), em estudos com adubação potássica, constataram que a cultura do rabanete responde significativamente à presença deste nutriente.

No $1^{\circ}$ ciclo, o tratamento 4 (T4) apresentou um crescimento da parte aérea de $16,1 \mathrm{~cm}$, enquanto o tratamento controle (T1) cresceu apenas $8,5 \mathrm{~cm}$, cerca de $50 \%$ a menos. Já no $2^{\circ}$ ciclo, T4 cresceu $13,6 \mathrm{~cm}$, enquanto o tratamento controle apenas $7,5 \mathrm{~cm}$, ou seja, $45 \%$ a menos.

$\mathrm{Na}$ figura 1(b), o mesmo comportamento (quadrático) observado para o comprimento da parte aérea foi constatado para o diâmetro do bulbo, o qual segue uma tendência crescente até um determinado valor, a partir do qual decresce. No $1^{\circ}$ ciclo, o valor máximo encontrado para o diâmetro do bulbo foi de $2,35 \mathrm{~cm}$, relativo a uma dose de $200 \%$ de ARB. Já no $2^{\circ}$ ciclo, o maior diâmetro do bulbo $(2,27 \mathrm{~cm})$ correspondeu a uma dose de $183 \%$ de água residuária. Apesar de ambos os ciclos terem alcançado rendimentos máximos similares, fica evidente que no $2^{\circ}$ ciclo o fator limitante apresentou-se doses mais baixas.

O decréscimo de ambos os parâmetros de crescimento do rabanete analisados, a partir de uma determinada dose de ARB residual, pode estar ligado ao aumento expressivo do íon sódio no solo. Estudos revelaram que o cátion que mais afeta o metabolismo é o sódio e sua distribuição nas culturas ocorre em maiores concentrações nas raízes, seguidas de caule, pecíolos e folhas, respectivamente (DUTRA, 2008).

$\mathrm{Na}$ figura 1(c), a massa seca do rabanete no $1^{\circ}$ ciclo apresentou um crescimento linear, de acordo com o aumento da dose de ARB no solo, não sendo observado um fator limitante para esse parâmetro. O T1 apresentou a menor massa seca da parte aérea $(0,1 \mathrm{~g})$ e o T4 e T5 apresentaram o maior valor $(0,5 \mathrm{~g})$, evidenciando um aumento de $500 \%$ na produção do rabanete como consequência do aumento da fertilidade do solo.

Freitas et al. (2004) observaram um aumento dos valores da altura do milho, índice de espigas e peso com a aplicação da ARS. Já Rodrigues et al. (2009) obtiveram um maior crescimento da cultura da mamoneira devido ao uso de água residuária de origem doméstica.

No $2^{\circ}$ ciclo, a massa seca da parte aérea alcançou seu máximo valor $(0,29 \mathrm{~g})$ quando a dose de ARB foi de $250 \%$, a partir da qual os valores de massa seca começaram a decrescer (tendência quadrática). Além disso, o máximo valor da massa seca da parte aérea do $2^{\circ}$ ciclo corresponde a apenas $50 \%$ do valor encontrado para o $1^{\circ}$ ciclo, enfatizando a diminuição de ARB residual no solo devido à utilização dos nutrientes pelo $1^{\circ}$ ciclo.

Comparando o tratamento controle com o de maior produção, observa-se que a maior massa seca da raiz encontrada ( $\mathrm{T} 4$ e $\mathrm{T} 5=0,3 \mathrm{~g}$ ) foi 3 vezes maior do que a massa seca da raiz do tratamento controle $(\mathrm{T} 1=0,1 \mathrm{~g})$.

A diminuição dos valores de massa seca da parte aérea do rabanete acima de $250 \%$ de ARB pode ser explicada pela presença de sódio. Fonseca et. al (2010) verificaram a diminuição da massa seca da parte aérea cerca de 4 vezes para os tratamentos que receberam doses de cloreto de sódio, se comparados aos tratamentos controle. De acordo com Filho et. al (1979), há uma tendência generalizada de decréscimo da produção da matéria seca de algodoeiros Mocó, quando altas doses de sódio são adicionadas.

$\mathrm{Na}$ figura 1(d), em ambos os ciclos, houve um aumento da massa seca da raiz à medida que a dose de ARB no solo crescia até um determinado ponto, a partir do qual houve o decréscimo do parâmetro analisado. No $1^{\circ}$ ciclo, o valor máximo de $0,85 \mathrm{~g}$ foi encontrado para uma dose de ARB de $232 \%$, enquanto no $2^{\circ}$ ciclo esse valor decresceu para $0,46 \mathrm{~g}$ a uma dose de $185 \%$ de ARB. Ou seja, o melhor desempenho encontrado no $2^{\circ}$ ciclo corresponde a apenas um pouco mais que $50 \%$ do $1^{\circ}$ ciclo. Mais uma vez, é verificado uma queda no 
desempenho do parâmetro estudado no $2^{\circ}$ ciclo, devido, provavelmente, a limitação de nutrientes.

Os tratamentos que obtiveram melhor e pior desempenho para esse parâmetro foram $\mathrm{T} 4$ e T1, respectivamente. No $1^{\circ}$ ciclo, T4 foi 10 vezes maior que T1 e, no $2^{\circ}$ ciclo, 6 vezes, mostrando como a ARB residual do solo pode aumentar a massa seca da raiz do rabanete significativamente. Maia (2011) verificou a importância da presença do potássio para o rabanete. Segundo a autora, a massa seca da raiz aumenta com a presença deste nutriente.

O decréscimo deste parâmetro, após valores de $232 \%$ de ARB para o $1^{\circ}$ ciclo e $185 \%$ de ARB para o $2^{\circ}$ ciclo, pode ser explicado pelo aumento da concentração de íons de sódio na solução do solo, trazendo prejuízos ao desenvolvimento da cultura, como já discutido anteriormente.

A figura 2 representa o gráfico radar construído com os parâmetros gerados no teste JIP, considerando-se como padrão $(1,0)$ o tratamento 1 (controle) para o $1^{\circ}$ e $2^{\circ}$ ciclo.

No $1^{\circ}$ ciclo, a presença da ARB residual em diferentes concentrações nos tratamentos provocou um visível incremento nos índices que descrevem a performance fotossintética (PIabs e PIabs, total), evidenciando que o aumento de nutrientes no solo permitiu um maior aproveitamento da energia luminosa absorvida, não causando danos ao aparato fotossintético.

$\mathrm{O}$ aumento do desempenho fotossintético foi diretamente proporcional ao residual de ARB no solo, não apresentando limitações quanto às doses mais elevadas. Para todos os tratamentos com ARB residual no solo, a performance fotossintética elevou-se, sendo a maior em T5, cerca de 2,5 vezes maior que em T1 (controle).

Outro parâmetro bastante discutido na literatura, a eficiência do FSII (FV/FM), caracteriza o aumento ou declínio da energia absorvida que é realmente utilizada no processo fotoquímico. No $1^{\circ}$ ciclo, foi observado um aumento da eficiência do FSII para todos os tratamentos com ARB residual, mostrando mais uma vez que a ARB no solo não provocou estresse ambiental. Entretanto, diversos autores verificaram insensibilidade deste parâmetro em plantas expostas aos estresses ambientais, tais como balance nutricional, excesso de luz, salinidade e estresse hídrico (SOUSA, 2012).

Em trabalho utilizando cinza vegetal, Silva et. al (2015) verificaram que tratamentos adubados com este recurso puderam desfrutar de uma maior disponibilidade de nutrientes que fazem parte dos processos fotossintéticos da planta, tais como potássio e magnésio, componentes centrais da molécula de clorofila. Assim, com o aumento

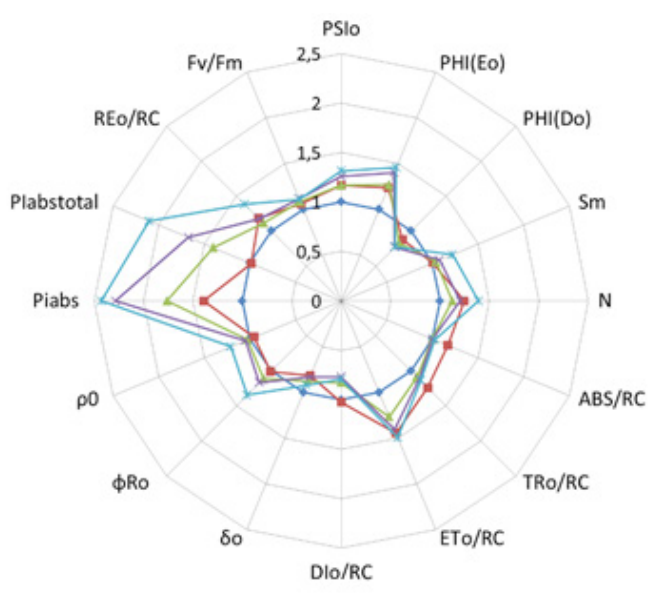

(a)

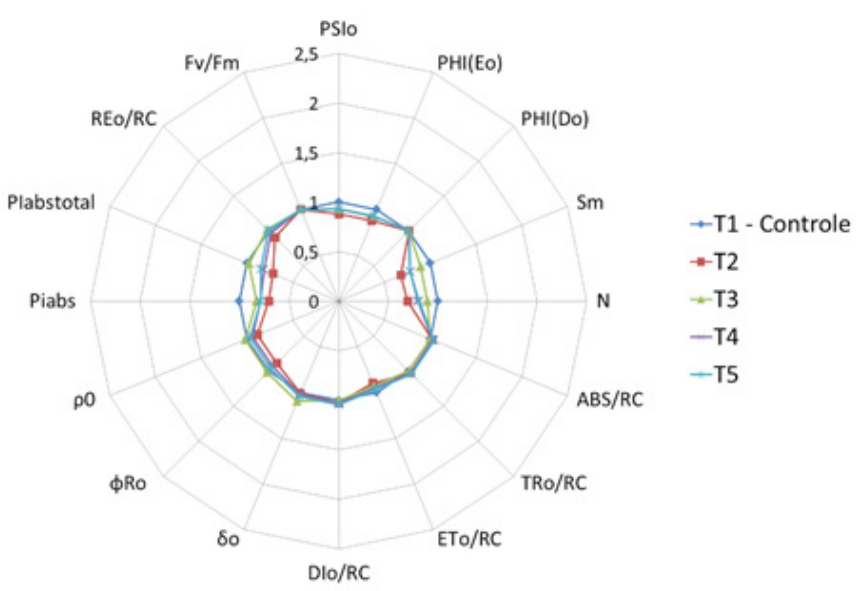

(b)

Figura 2. Radar-plot dos parâmetros de fluorescência da clorofila a derivados do Teste JIP em folhas de rabanete adaptadas ao escuro para o $1^{\circ}$ (a) e $2^{\circ}$ ciclo (b). Valores expressos relativos ao controle (valor normalizado para 1). 
EFEITO RESIDUAL DA FERTIRRIGAÇÃO COM ÁGUA RESIDUÁRIA DE BOVINOCULTURA NA QUALIDADE...

da fotossíntese, ocorre o aumento de compostos orgânicos que são fundamentais para o aumento vegetativo.

No $2^{\circ}$ ciclo, praticamente todos os parâmetros de fluorescência foram similares ao controle, demonstrando uma queda na performance da fotossíntese, uma vez que o solo não apresenta a mesma concentração de $\mathrm{ARB}$ residual do $1^{\circ}$ ciclo. Neste ciclo, o T1 (controle) apresentou o melhor desempenho, seguido de T3, T5, T4 e T2, respectivamente.

Na figura 3, apresenta-se o primeiro sintoma de deficiência observado durante o experimento ( $1^{\circ}$ ciclo), cerca de 20 dias após o plantio. Os tratamentos circulados em vermelho representam T1, ou seja, aqueles que não possuíam doses $A R B$ no solo. Visivelmente, nesse tratamento, o rabanete apresentou atraso no florescimento e folhas menores, destacando a baixa fertilidade deste solo em relação aos outros. Segundo Malavolta et al. (1997), os tipos de alterações detectadas sugerem um solo deficiente em nitrogênio, fósforo e enxofre. De fato, a deficiência destes minerais pôde ser constatada pela análise do solo realizada antes do início do experimento, exceto o enxofre, o qual não foi analisado.

Nas figuras 4(a) e 4(b), podem ser observados sinais de clorose e início de necrose foliar em $\mathrm{T} 1$, poucos dias precedendo a colheita ( $1^{\circ}$ ciclo).

A clorose (amarelecimento ou branqueamento das folhas) das folhas mais velhas ocorre, principalmente, devido à deficiência de nitrogênio, fósforo, potássio e magnésio. Já a necrose foliar, detectada nas margens das folhas, é decorrente da

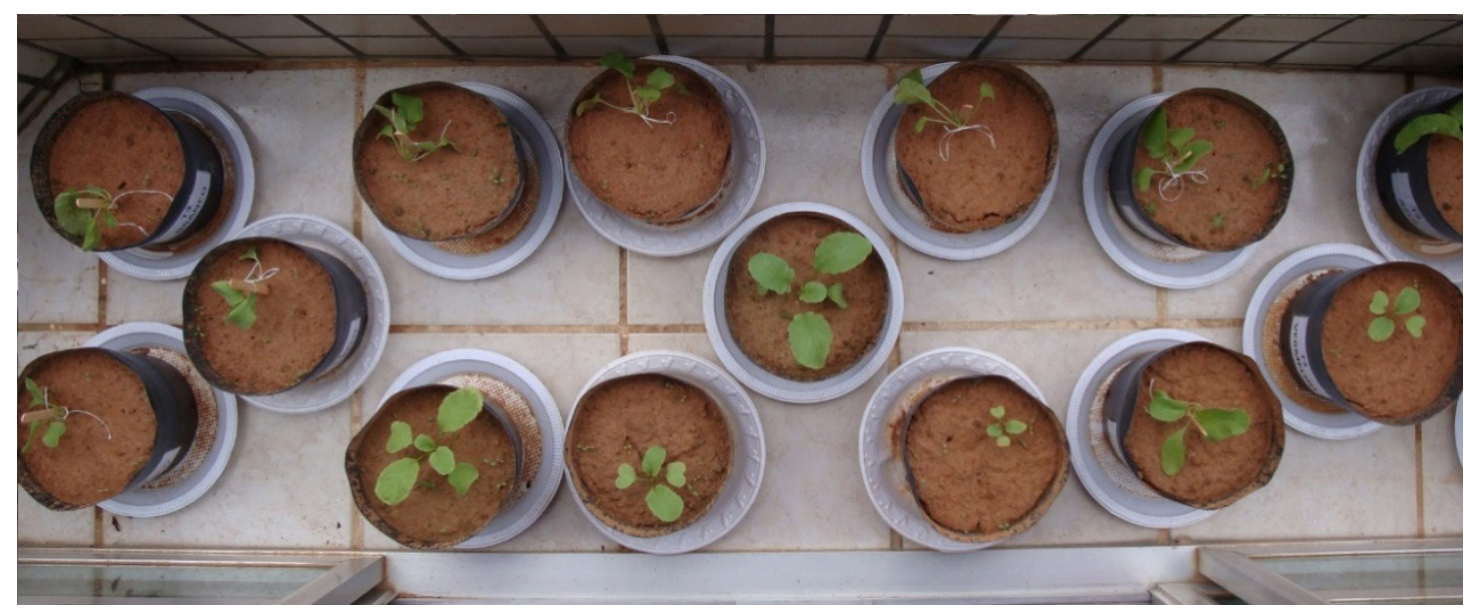

Figura 3. Primeiro sinal de deficiência de nutrientes observado $\left(1^{\circ}\right.$ ciclo $)$

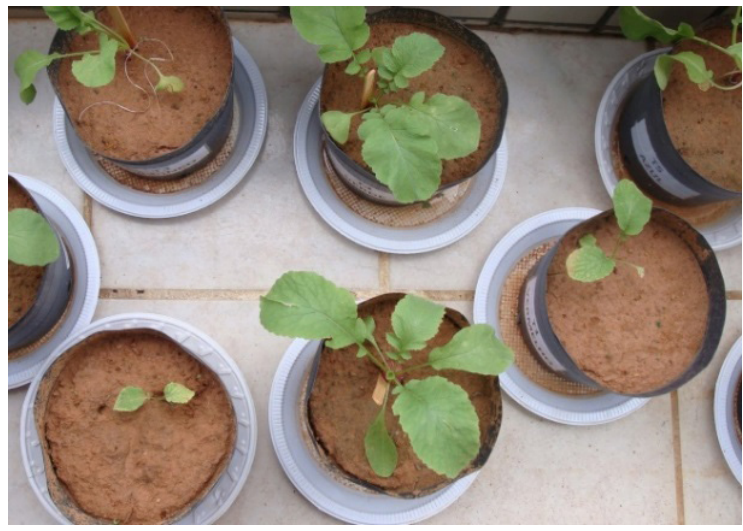

(a)

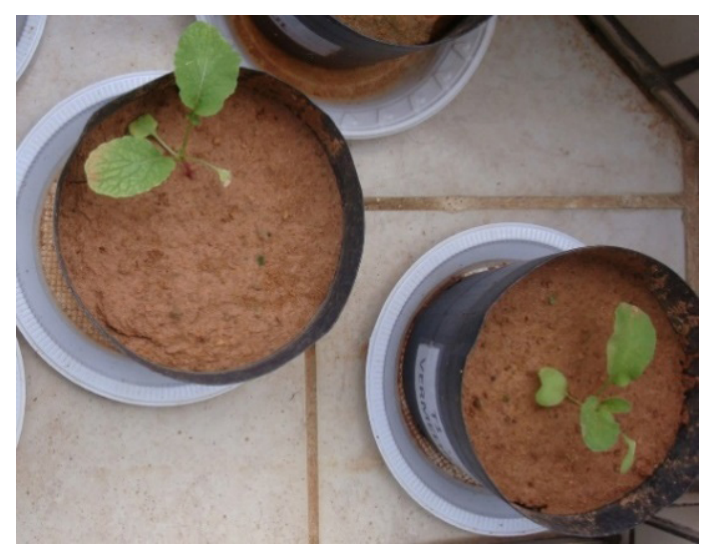

(b)

Figura 4. Sinais de clorose foliar 
deficiência de enxofre e potássio (MALAVOLTA et al.,1997).

Vale ressaltar que o excesso de alumínio no solo pode fazer com que as folhas apresentem os mesmos sintomas casados pela falta de fósforo, potássio, cálcio e magnésio (MALAVOLTA et al.,1997). No entanto, não é o caso deste trabalho, uma vez que os teores de alumínio foram ínfimos ou nulos nos tratamentos.

$\mathrm{Na}$ figura 5, pode ser observada uma coloração diferenciada para o tratamento 3 (T3).

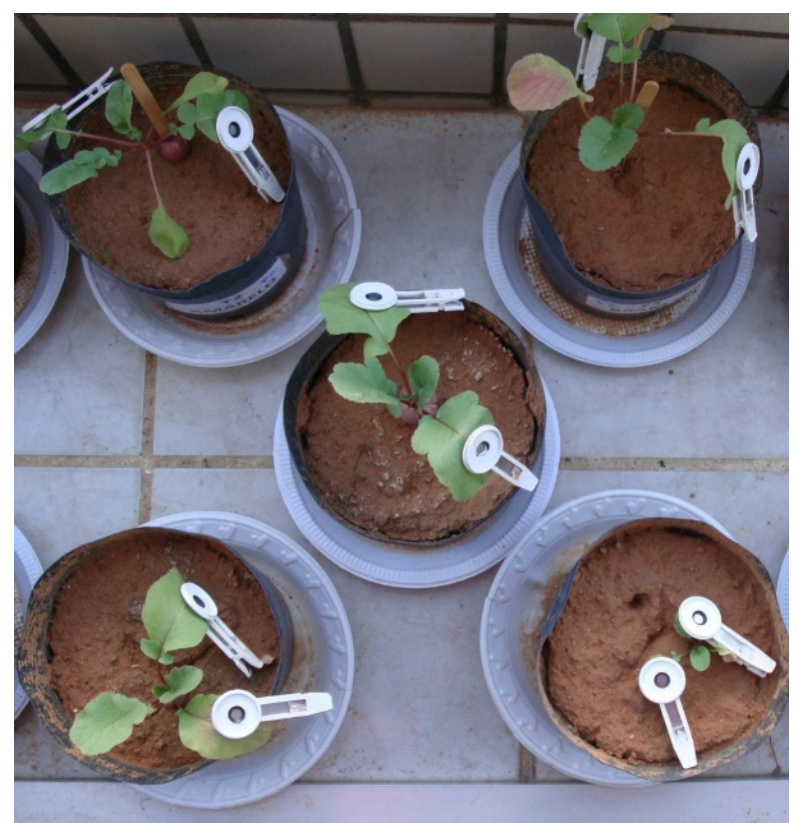

Figura 5. Coloração avermelhada na folha do T3

Segundo Malavolta et al. (1997), a coloração avermelhada das folhas é indicativo de deficiência de três minerais: magnésio, enxofre e boro. Apesar de outros tratamentos possuírem maior deficiência desses nutrientes, a coloração avermelhada só foi observada nesta réplica do $\mathrm{T} 3$ do $1^{\circ}$ ciclo, indicando que podem ter ocorrido interferências ambientais em algum momento do experimento.

$\mathrm{Na}$ figura 6 abaixo, são apresentados todos os tratamentos do $2^{\circ}$ ciclo, logo após a colheita. Visivelmente, o desenvolvimento do bulbo dos rabanetes se diferenciaram bastante de acordo com a ARB presente no solo. O tratamento 4 (T4) apresentou o melhor desenvolvimento do bulbo, enquanto o tratamento T1 obteve o menor desenvolvimento do bulbo.

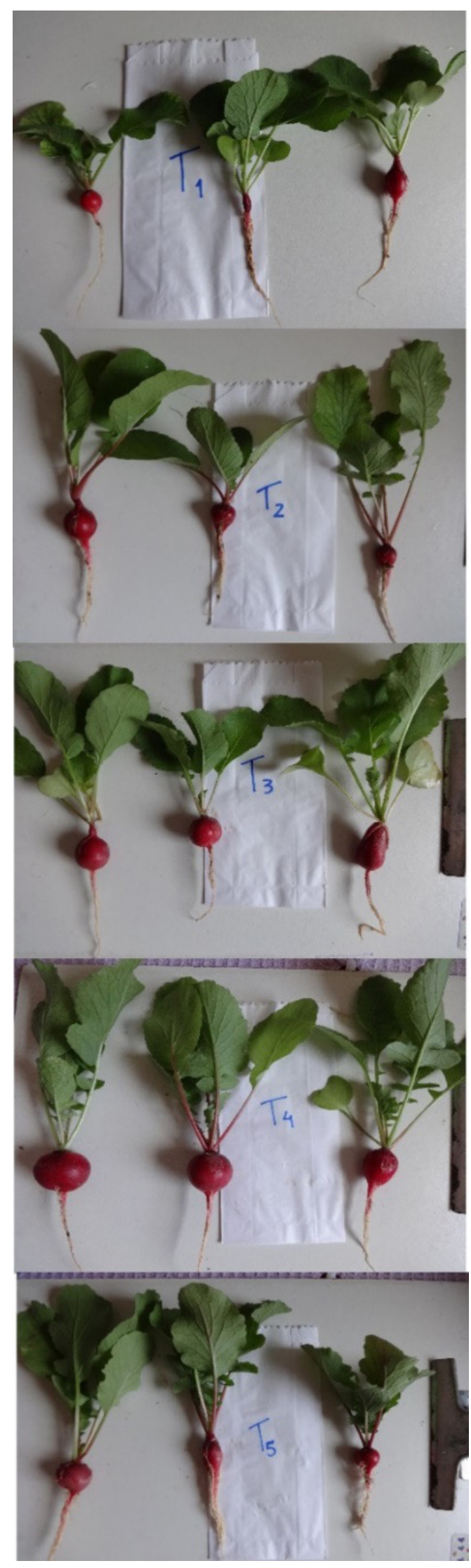

Figura 6. Tratamentos do $2^{\circ}$ ciclo logo após a colheita 
EFEITO RESIDUAL DA FERTIRRIGAÇÃO COM ÁGUA RESIDUÁRIA DE BOVINOCULTURA NA QUALIDADE...

\section{CONCLUSÕES}

- As doses de água residuária de bovinocultura, mesmo após meses da aplicação, foram responsáveis pela melhora significativa da qualidade do solo argilo-arenoso, principalmente, segundo o teor de nutrientes essenciais ao crescimento das culturas, o que foi visto pela resposta do bioindicador utilizado no trabalho. Entretanto, vale ressaltar que os tratamentos que receberam altas doses de água residuária de bovinocultura apresentaram elevados teores de sódio, o que pode ter sido responsável pela diminuição do desempenho do rabanete.

- De modo geral, para os parâmetros de crescimento e produção do bioindicador analisado, a água residuária no solo proporcionou um aumento no desempenho do rabanete, se comparado ao tratamento controle. Porém, foi observado o decréscimo no valor desses parâmetros no caso de disposição de elevadas concentrações de água residuária no solo.

- A aplicação de doses de água residuária de bovinocultura, que suplantam expressivamente a demanda nutricional das culturas, pode ocasionar o aumento expressivo dos níveis de sódio, os quais permanecem no solo, prejudicandosuaqualidadee odesenvolvimento de culturas plantadas futuramente.

\section{AGRADECIMENTOS}

Ao Laboratório de Monitoramento Ambiental I - Água e Efluentes da UFRRJ, pelas análises concedidas.

\section{REFERÊNCIAS BIBLIOGRÁFICAS}

CESAMA. 2010. Disponível em: <http://www. cesama.com.br/?pagina $=$ hidrografia $>$. Acessado em 10 jan 2016.

EMBRABA. Manual de Métodos de Análise de Solo. 2011. Disponível em: $<$ https://www.google. com.br/url? sa $=\mathrm{t} \& \mathrm{rct}=\mathrm{j} \& \mathrm{q}=\&$ esrc $=\mathrm{s} \&$ source $=$ web
$\& c d=1 \&$ cad $=$ rja\&uact $=8 \&$ ved $=0$ ahUKEwjQnf2 2 2MLUAhXChZAKHdtSDpQQFggpMAA\&url= https $\% 3 \mathrm{~A} \% 2 \mathrm{~F} \% 2 \mathrm{Fwww}$.agencia.cnptia.embrapa. br\%2FRepositorio\%2FManual\%2Bde $\% 2 \mathrm{BMe}$ todos_000fzvhotqk02wx5ok0q43a0ram $31 \mathrm{wtr}$. GzICORoWc9OM5aYSSmH2A\&sig2=Wt-j87 WcW62B1YPFvSohA>. Acessado em 20 mar 2016.

ERTHAL, V.J.T. et al. Alterações físicas e químicas de um Argissolo pela aplicação de água residuária de bovinocultura. Revista Brasileira de Engenharia Agrícola e Ambiental. v.14, n.5, p.467-477, 2010. Disponível em: <http:// www.scielo.br/pdf/rbeaa/v14n5/a03v14n5.pdf $>$. Acessado em 10 out. 2015.

ERTHAL, V.J.T. Características fisiológicas, nutricionais e rendimento de forrageiras fertigadas com água residuária de bovinocultura. Revista Brasileira de Engenharia Agrícola e Ambiental. v.14, n.5, p.458-466. Campina Grande, PB, 2010. Disponível em: $<$ http://www.scielo.br/scielo.php?script=sci_artte $\mathrm{xt \& pid}=\mathrm{S} 1415-43662010000500002>$. Acessado em 18 jan 2016.

DUTRA, A.T.B. Distribuição de $\mathrm{Na}^{+}$e $\mathrm{Cl}^{-}$em plantas jovens de feijão caupi expostas a estresse salino e temperatura elevada.(Dissertação)Curso de Pós-Graduação em Agronomia, Fortaleza, Ceará, Brasil, 2008. Disponível em: $<$ http://www. repositorio.ufc.br/bitstream/riufc/5019/1/2008 dis_atbdutra.pdf $>$. Acessado em 15 fev. 2016.

FAO. Organização das Nações Unidas para Alimentação e Agricultura. FAO discute demanda mundial por alimentos. Notícia. 2009. Disponível em: $\quad<$ https://www.fao.org.br/FAOddma.asp $>$. Acessado em 15 jan 2016.

FERREIRA, P. A. Transporte de solutos no solo. Viçosa - MG: UFV, 2007. 30p. (Apostila).

FILHO, J.V.C. et. al. Efeito do sódio na produção de matéria seca em mudas de duas cultivares de algodoeiro mocó (gossypiumhirsutum l., var. Maria galante hucth.): cv. '9193' e 'c-71'.Anais 
da E.S.A. "Luiz Queiroz". Volume XXXVI, 1979. Disponível em: <http://www.scielo.br/pdf/aesalq/ v36/32.pdf>. Acessado em: 17 jan. 2016.

FONSECA, A.S. et. al. Efeito da salinidade na germinação de sementes de rabanete. XIV Encontro Latino Americano de Iniciação Científica e X Encontro Latino Americano de Pós-Graduação - Universidade do Vale do Paraíba. 2010. Disponível em: <http://www.inicepg.univap.br/ cd/INIC_2010/anais/arquivos/RE_0826_0863_01. pdf>. Acessado em 04 fev. 2016.

FOOD AGRICULTURAL ORGANIZATION. 2015. Food Outlook. Biannual Report on Global Food Markets.Analysis. May, 2015. Disponível em: http://www.fao.org/3/a-i4581e.pdf. Acessado em: 17 jan. 2016.

FREITAS, W.S. et al. Efeito da aplicação de águas residuária de suinocultura sobre a produção do milho para silagem. Revista Brasileira de engenharia Agrícola e Ambiental. Campina Grande, PB, DEag/UFCG. V.8, n.1, p.120-125, 2004. Disponível em: <http:// www.scielo.br/scielo.php? pid=S 1415 $43662004000100018 \&$ script $=$ sci_arttext $>$. Acessado em 09 jan 2016.

IFCN, International Farm Comparison Network. A summary of results from the IFCN Dairy Report 2012. Disponível em: <http://www. milkproduction.com/Global/IFCN\%20Dairy\%20 Report\%202012-press\%20release.pdf $>$. Acessado em 09 out. 2015.

IBGE - Instituto Brasileiro de Geografia e Estatística. Produção de Pecuária Municipal. v.39, p.1-63, Rio de Janeiro, 2011. Disponível em: $\quad<\mathrm{ftp} / / / \mathrm{ftp}$. ibge.gov.br/Producao_Pecuaria/ Producao_da_Pecuaria_Municipal/2011/ ppm2011.pdf $>$. Acessado em 08 out. 2015.

MAIA, P.M.E. et.al. Desenvolvimento e qualidade do rabanete sob diferentes fontes de potássio. Revista verde de agroecologia e desenvolvimento sustentável. Grupo verde de agricultura alternativa. Revista Verde. v.6, n.1, p.148-153. Mossoró,
RN, Brasil, 2011. Disponível em: <http://www. gvaa.com.br/revista/index.php/RVADS/article/ view/531>. Acessado em 04 fev. 2016.

MALAVOLTA, E; VITTI, G.C; OLIVEIRA, S.A. Avaliação do estado nutricional das plantas princípios e aplicações. Associação Brasileira para Pesquisa de Potássio e do Fosfato. $2^{\text {a }}$ Edição, 319p. Editora Potafos. São Paulo, 1997.

MATOS, A.T. Poluição Ambiental - Impactos no Meio Físico. Editora UFV. 260p. Viçosa, MG, 2010.

RODRIGUES, L.N. et al. Crescimento e produção de bagas da mamoneira irrigada com água residuária doméstica. Revista Brasileira de Engenharia Agrícola e Ambiental. v.13, (Suplemento), p.825-835. Campina Grande, PB, 2009. Disponível em: $<$ http://www.scielo.br/pdf/ rbeaa/v13s0/v13s0a03.pdf $>$. Acessado em 18 jan 2016.

SCHOSSLER, T.R. et. al. Salinidade: efeitos na fisiologia e na nutrição mineral de plantas. Enciclopédia Biosfera, Centro Científico Conhecer, Goiânia, v.8, n.15; p.1563.2012. Disponível em: $<$ http://www.conhecer.org.br/enciclop/2012b/ ciencias $\% 20$ agrarias/salinidade $\% 20$ efeitos.pdf $>$. Acessado em 18 jan 2016.

SILVA, J.B.G. Uso de água residuária de bovinocultura de leite no cultivo da figueira (Ficuscarica L.): efeitos no solo e na cultura. 2012. Tese (Doutorado em Engenharia Agrícola). Universidade Federal de Viçosa. Viçosa, MG. 2012.

SILVA, R.T. et. al. Tolerância do rabanete ao encharcamento do solo. Revista verde de agroecologia e desenvolvimento sustentável. Grupo verde de agricultura alternativa. Revista Verde. v.7, n.1, p. 25-33. Mossoró, RN, Brasil, 2012. Disponível em: <http://www.gvaa.com.br/ revista/index.php/RVADS/article/view/1162>. Acessado em 04 fev. 2016.

SOUSA, C.P. Ação de herbicidas sobre a atividade 
EFEITO RESIDUAL DA FERTIRRIGAÇÃO COM ÁGUA RESIDUÁRIA DE BOVINOCULTURA NA QUALIDADE...

fotossintética de plantas com metabolismo C3 e

C4. Universidade Federal de Pelotas. Programa de pós-graduação em fisiologia vegetal. (Tese Doutorado). Pelotas, 2012. Disponível em: $<$ http:// repositorio.ufpel.edu.br/handle/123456789/1989>. Acessado em 04 fev. 2016

SOUSA, G.G. et al. Adubação potássica aplicada por fertirrigação e pelo método convencional na cultura do amendoim. Revista Brasileira de Engenharia Agrícola e Ambiental. V.17, n. 10, p 1055-1060, 2013. Disponível em:
$<$ http://www.scielo.br/scielo.php?pid=S1415$43662013001000005 \mathrm{script}=\mathrm{sci}$ _arttext $>$. Acessado em 05 dez 2015.

UNITED NATIONS.Department of Economic and Social Affairs, Population Division (2015).World Population Prospects: The 2015 Revision, World Population 2015 Wallchart. 2015. Disponível em: $\quad<$ http://esa.un.org/unpd/wpp/Publications/ Files/World_Population_2015_Wallchart.pdf $>$. Acessado em 17 jan 2016. 